Article

\title{
Influence of Carbon Black and Silica Fillers with Different Concentrations on Dielectric Relaxation in Nitrile Butadiene Rubber Investigated by Impedance Spectroscopy
}

\author{
Gyung-Hyun Kim ${ }^{1,+}$, Young-Il Moon ${ }^{2,+}$, Jae-Kap Jung ${ }^{3, *}$, Myung-Chan Choi ${ }^{4}$ and Jong-Woo Bae ${ }^{4}$ \\ 1 Department of Physics and Research Institute of Natural Science, Gyeongsang National University, \\ Jinju 52828, Korea; 2016010673@gnu.ac.kr \\ 2 Department of Electrical Engineering, Pohang University of Science and Technology, Pohang 37673, Korea; \\ yimoon@postech.ac.kr \\ 3 Hydrogen Energy Materials Research Center, Korea Research Institute of Standards and Science, \\ Daejeon 34113, Korea \\ 4 Rubber Research Division, Korea Institute of Footwear \& Leather Technology, Busan 47154, Korea; \\ mcchoi@kiflt.re.kr (M.-C.C.); jwbae@kiflt.re.kr (J.-W.B.) \\ * Correspondence: jkjung@kriss.re.kr \\ + These authors contributed equally to this work.
}

\section{check for}

updates

Citation: Kim, G.-H.; Moon, Y.-I.; Jung, J.-K.; Choi, M.-C.; Bae, J.-W. Influence of Carbon Black and Silica Fillers with Different Concentrations on Dielectric Relaxation in Nitrile Butadiene Rubber Investigated by Impedance Spectroscopy. Polymers 2022, 14, 155. https://doi.org/ $10.3390 /$ polym 14010155

Academic Editor:

Mariaenrica Frigione

Received: 29 November 2021 Accepted: 28 December 2021 Published: 31 December 2021

Publisher's Note: MDPI stays neutral with regard to jurisdictional claims in published maps and institutional affiliations.

Copyright: (c) 2021 by the authors. Licensee MDPI, Basel, Switzerland. This article is an open access article distributed under the terms and conditions of the Creative Commons Attribution (CC BY) license (https:/ / creativecommons.org/licenses/by/ $4.0 /)$.

\begin{abstract}
In neat nitrile butadiene rubber (NBR), three relaxation processes were identified by impedance spectroscopy: $\alpha$ and $\alpha^{\prime}$ processes and the conduction contribution. We investigated the effects of different carbon black (CB) and silica fillers with varying filler content on the dielectric relaxations in NBR by employing a modified dispersion analysis program that deconvolutes the corresponding processes. The central frequency for the $\alpha^{\prime}$ process with increasing high abrasion furnace (HAF) CB filler was gradually upshifted at room temperature, while the addition of silica led to a gradual downshift of the center frequency. The activation energy behavior for the $\alpha^{\prime}$ process was different from that for the central frequency. The use of HAF CB led to a rapid increase in DC conductivity, resulting from percolation. The activation energy for the DC conductivity of NBRs with HAF CB decreased with increasing filler, which is consistent with that reported in different groups.
\end{abstract}

Keywords: nitrile butadiene rubber; dielectric relaxation; impedance spectroscopy; carbon black; activation energy

\section{Introduction}

Nitrile butadiene rubber (NBR) is the most commonly utilized elastomer in the automotive, aeronautical, and nuclear industries [1,2]. NBR resists oil-based hydraulic fluids, vegetable oils, flame retardant liquids, grease, water, and gas [3,4]. Although NBR is known to exhibit numerous outstanding properties, enhancement fillers are necessarily added to NBR to attain appropriate properties for specific applications, such as low gas permeation at high pressure. The reinforcement of elastomers improves physical properties such as tear strength, tensile strength, hardness, abrasion resistance, and thermal properties. A wide variety of particulate fillers are used in the rubbery polymer industry for various purposes, of which the most important are reinforcement, reduction in material costs, and improvements in processing [5,6]. Physical properties such as volume swelling, density, chemical stability, and heat resistance of rubber vulcanizates are also improved through incorporation with fillers such as carbon black (CB) [7] and silica [8].

$\mathrm{CB}$ and silica have been used as the main reinforcing agents in rubber compounds, but their surface chemistries are very different [9]. CB is one of the most widely used conductive nanoparticles in industrial applications and is considered a suitable candidate because of its low cost and good dispersion ability. When CB is compounded with rubbers, the tensile strength, tear strength, modulus, and abrasion resistance are found to be 
increased [10,11]. For this reason, $\mathrm{CB}$ has been extensively exploited in numerous rubber engineering products [12]. On the other hand, silica provides a unique combination of tear strength, abrasion resistance, aging resistance, and adhesion properties [13]. In tire treads, silica yields a lower rolling resistance at equal wear resistance and wet grip than CB [14]. Synthetic silica is currently extensively used to improve physical and mechanical parameters, such as tensile strength and elongation of silicone rubber vulcanisates [12]. The use of silica fillers enables the physical and mechanical properties of NBR rubber vulcanisates to be improved $[15,16]$.

Under these circumstances, it is necessary to research the effects of fillers on these properties in rubber composites by employing a non-destructive microscopic technique. Impedance spectroscopy provides useful ways to clarify the dielectric relaxation and related electrical properties of rubber composites. Thus, it has been extensively employed to investigate the nature of local molecular motion associated with relaxation behavior [17-21]. However, limited investigations of the influence of fillers on dielectric properties in NBR have taken place thus far [22,23]. It is a crucial task to provide useful information on dielectric responses of NBRs blended with various filling agents in rubber applications and related academic studies. Therefore, the main focus of this investigation lies in the influences of the various fillers on the dynamic relaxation properties of NBR.

Recently, we characterized several relaxation processes embedded with NBR, ethylene propylene diene monomer (EPDM), and fluoroelastomers (FKM) with a self-developed dispersion analysis program by employing the modified numerical method of nonlinear optimization [24,25]. As a continuation of that line of research, the present investigations are concerned with systematic studies of the electrical properties of blends of neat NBR mixed with CB and silica. The effect of filler loading on the dielectric relaxation process and DC conductivity was studied in these composites in an attempt to understand the corresponding mechanism and filler-induced effects. Thus, the present paper addresses conductive rubber based on blends of NBR in different proportions and filled with different amounts of conductive CB and silica. The effect of the filler on the $\alpha$ and $\alpha^{\prime}$ processes and conductivity are discussed in terms of the corresponding process motion, activation energy, and glass transition.

\section{Materials and Methods}

\subsection{Sample Composition}

KNB $35 \mathrm{~L}$ (Kumho NBR) with an acrylonitrile content of $34 \mathrm{wt} \%$, produced by Kumho petrochemical group, was used as the main component for neat NBR rubber. The compound recipe for the composition for NBR specimens with $\mathrm{CB}$ and silica fillers is given in Tables 1 and 2, respectively, which includes one neat NBR without any added filler, six samples with CB, and three samples with silica filler. In this study, we employed two types of CB prepared using a high abrasion furnace (HAF) and a medium thermal furnace (MT) by Orion Engineer Carbon, which have particle sizes of $28-36 \mathrm{~nm}$ and $250-350 \mathrm{~nm}$, respectively. The detailed ASTM (American Society for Testing and Materials) classifications of our CB particles are listed in Table S1. The silica (specific grade Zeosil ${ }^{\circledR} 175$ ) was produced by Solvay, which has a specific surface area of $175 \mathrm{~m}^{2} / \mathrm{g}$.

Table 1. Compositions of the NBR with HAF and MT CB fillers.

\begin{tabular}{cccccccc}
\hline Composition & Neat NBR & NBR-H20 & NBR-H40 & NBR-H60 & NBR-M20 & NBR-M40 & NBR-M60 \\
\hline KNB 35 L & 100 & 100 & 100 & 100 & 100 & 100 & 100 \\
ZnO & 3.0 & 3.0 & 3.0 & 3.0 & 3.0 & 3.0 & 3.0 \\
St/A * & 1.0 & 1.0 & 1.0 & 1.0 & 1.0 & -0 & 1.0 \\
HAF N330 & - & 20 & 40 & 60 & - & - & 40 \\
MT N990 & - & - & - & 1.5 & 1.5 & 1.5 & 0.7 \\
S & 1.5 & 1.5 & 0.5 & 0.7 & 0.7 & 0.7 \\
TBBS & 0.7 & 0.7 & 0.7 & & & 0.7 \\
\hline
\end{tabular}

* St/A: stearic acid; ${ }^{+}$TBBS: N-tert-butyl-2-benzothiazole sulfenamide. 
Table 2. Compositions of the NBR with silica fillers.

\begin{tabular}{cccc}
\hline Composition & NBR-S20 & NBR-S40 & NBR-S60 \\
\hline KBR 35 L & 100 & 100 & 100 \\
ZnO & 3.0 & 3.0 & 3.0 \\
St/A & 1.0 & 1.0 & 1.0 \\
Silica S-175 & 20 & 40 & 60 \\
Si-69 & 1.6 & 3.2 & 4.8 \\
PEG $^{\#}$ & 0.8 & 1.6 & 2.4 \\
S & 1.5 & 1.5 & 1.5 \\
TBBS $^{+}$ & 0.7 & 0.7 & 0.7 \\
\hline
\end{tabular}

× Si-69: silane coupling agent; ${ }^{\# ~ P E G: ~ p o l y e t h y l e n e ~ g l y c o l ; ~}{ }^{+}$TBBS: N-tert-butyl-2-benzothiazole sulfenamide.

The vulcanizates were filled with $20 \mathrm{phr}, 40 \mathrm{phr}$, and $60 \mathrm{phr}$ (parts per 100 parts of rubber). For simplicity, the NBR blends mixed with fillers were named NBR-Hx, NBR-My, and NBR-Sz, where $\mathrm{x}, \mathrm{y}$, and $\mathrm{z}$ indicate the phr content for HAF, MT, and silica, respectively. For example, NBR-S40 is NBR filled with silica of $40 \mathrm{phr}$.

A two-stage mixing was employed, using the internal mixer with two banbury rotors and two open roll mills of eight inches to prepare NBR composites. The first stage of mixing (masterbatch) was compounding of NBR rubber, reinforcing the fillers such as carbon blank and precipitated silica, and processing the aids such as $\mathrm{ZnO}$ and the stearic acid with an internal mixer (3L kneader, Moriyama Co., Tokyo, Japan). The filling factor was fixed to 0.8 , and the starting operation temperature of kneader was set to $80^{\circ} \mathrm{C}$. The rotor speed was set to $30 \mathrm{rpm}$. The NBR rubber was added to $3 \mathrm{~L}$ kneader and masticated for $3 \mathrm{~min}$. After this, the reinforcing filler and the processing aids were incorporated for $10 \mathrm{~min}$. At the second stage of mixing, open roll mills were used to add the curing agents and accelerating agents into the masterbatch composite. The mixer was set to a nip opening of $3 \mathrm{~mm}$ between the rolls. The masterbatch was added to the roller and mixed for $1 \mathrm{~min}$. The sulfur and TBBS were then added and mixed into the batch, which took about $2 \mathrm{~min}$. The mixer nip was opened, and then the finished batch was cut into sheets. The mixing time was kept uniform for all composites.

Vulcanizate sheets of the composites with a thickness of $3 \mathrm{~mm}$ for impedance testing were prepared by compression molding in a hydraulic press at $150{ }^{\circ} \mathrm{C}$ according to the optimum cure time obtained from the oscillating disk rheometer.

\subsection{Impedance Spectroscopy}

The impedance spectroscopy system includes a temperature chamber, an impedance analyzer (VSP-300 BioLogic, Seyssinet-Pariset, France), and a PC with a dispersion analysis program for controlling the temperature chamber and processing the measured impedance data. The configurations of the system are well described in previous papers [24,25], and the description of the analysis software is found in Figure S1 of the Supplementary Materials. All of the specimens were prepared with a cylindrical shape with a diameter of $70 \mathrm{~mm}$ and a thickness of $3 \mathrm{~mm}$, and both top and bottom surfaces were covered by the copper electrodes.

The impedance measurement was conducted in the frequency range of $0.01 \mathrm{~Hz}$ to $1 \mathrm{MHz}$ and a temperature range of $233 \mathrm{~K}$ to $403 \mathrm{~K}$ over $5 \mathrm{~K}$ intervals at an applied voltage of $1000 \mathrm{mV}$. The real and imaginary dielectric permittivity was obtained from the impedance measurement by the following relation:

$$
\varepsilon^{\prime}=\frac{d}{\omega \varepsilon_{0} A} \frac{Z^{\prime \prime}}{\left(Z^{\prime 2}+Z^{\prime \prime 2}\right)}, \quad \varepsilon^{\prime \prime}=\frac{d}{\omega \varepsilon_{0} A} \frac{Z^{\prime}}{\left(Z^{\prime 2}+Z^{\prime \prime 2}\right)}
$$

where $Z^{\prime}$ and $Z^{\prime \prime}$ are the real and imaginary parts of the impedance, respectively. $d$ is the thickness of the sample, $A$ is the area of the sample, and $\omega$ is the angular frequency. $\varepsilon_{0}$ is the vacuum permittivity, $\varepsilon_{0}=8.854 \times 10^{-12} \mathrm{~F} / \mathrm{m}$. 


\subsection{Transmission Electron Microscopy and Differential Scanning Calorimeter}

The microstructure of NBR samples was investigated with a combination of the focused ion beam (FIB) and transmission electron microscopy (TEM). Thin foil specimens for TEM observation were prepared by a FIB technique. Morphology, distributions, and size of the filler particles in NBR specimens were observed with a TEM (TECHNAI F20, FEI company) operated at an accelerating voltage of $200 \mathrm{kV}$.

Dynamic glass transition temperature $\left(\mathrm{T}_{\mathrm{g}}\right)$ for NBR specimens was measured by using a differential scanning calorimeter (DSC, Q-600 analyzer of TA instruments). The measurements were conducted with a heating rate of $1 \mathrm{~K} / \mathrm{min}$ in the temperature range from $193 \mathrm{~K}$ to $353 \mathrm{~K}$. The difference in heat flow (W/g) into the sample and the reference pans were recorded as a function of temperature. From the measured heat flow curves, $\mathrm{T}_{\mathrm{g}}$ was calculated by TA universal analysis software, a program that was also provided by TA instruments.

\section{Relaxation Process and Model Function}

\section{1. $\alpha$ Relaxation Process}

The $\alpha$ relaxation process is mainly related to the segmental motion of the amorphous polymer chains and glass transition. The $\alpha$ relaxation observed normally at lower temperatures $(250 \mathrm{~K}-300 \mathrm{~K})$ and high frequencies $\left(10^{6}-10^{10} \mathrm{~Hz}\right)$ has a strong temperature dependence with non-Arrhenius characteristics. It can be described as a Vogel-FulcherTammann-Hesse (VFTH) function:

$$
f_{0}=f_{\infty} \exp \left[-\frac{E_{a}}{k_{B}\left(T-T_{0}\right)}\right]
$$

where $f_{0}$ is the central frequency of the $\alpha$ process in the frequency domain, $f_{\infty}$ is a constant, and $k_{B}$ is the Boltzmann constant. $T$ is the temperature, and $T_{0}$ is the so-called ideal glass transition or Vogel temperature, which is normally found to be $30-70 \mathrm{~K}$ below the glass transition temperature $\left(T_{g}\right)[19]$.

\section{2. $\alpha^{\prime}$ Relaxation Process}

The $\alpha^{\prime}$ relaxation process contributes to the motion of the end-to-end vector in polymer segmental chains, which is observed only in polymer type A. According to Stockmayer [26] and Block [27], the vector sum of the total dipole moment in polymer chains consists of the parallel direction with the segmental chain (backbone chain), called polymer type A. For this polymer type, when proportional to the fluctuation of the end-to-end vector of the polymer chain, $\alpha^{\prime}$ relaxation can be observed. $\alpha^{\prime}$ relaxation is usually called normal mode relaxation. Similar to $\alpha$ relaxation, the central frequency of $\alpha^{\prime}$ relaxation has nonlinear temperature dependence, and the relaxation rate of $\alpha^{\prime}$ can be described by the VFTH temperature dependence.

\subsection{Conductivity and Model Function}

The origin of DC conductivity in polymers can be regarded as a transport phenomenon by considering the movement of the charge carriers such as ionic impurities [28] and thermally excited electrons between valance and conduction band [29]. In this study, the measurement of the DC conductivity using dielectric spectroscopy was obtained by the relation between Maxwell equation and Jonscher's power law given by

$$
\begin{gathered}
\nabla \times \mathbf{H}=\left(\sigma_{t o t}+j \omega \varepsilon\right) \mathbf{E}=j \omega \varepsilon\left(1-j \frac{\sigma_{t o t}}{\omega}\right) \mathbf{E}=j \omega \varepsilon^{*} \mathbf{E} \\
\sigma_{t o t}=\sigma_{d c}+A \omega^{n}
\end{gathered}
$$

where $\mathbf{H}$ and $\mathbf{E}$ indicate the magnetic and electric field vectors, respectively. The $\sigma_{\text {tot }}$ is the total conductivity of the sample, $A \omega^{n}$ is the pure dispersive component of AC conductivity with a characteristic of power law in terms of angular frequency $\omega$ and exponent 
$n(0 \leq n \leq 1)$, and $\mathrm{A}$ is a constant that determines the strength of polarizability [30]. The temperature dependency of DC conductivity $\left(\sigma_{d c}\right)$ is described by the Arrhenius equation:

$$
\sigma_{d c}=\sigma_{0} \exp \left[-\frac{E_{a}}{k_{B} T}\right]
$$

where $\sigma_{0}$ is the pre-exponential factor and $E_{a}$ is the activation energy.

In investigating the dynamics of the corresponding relaxation process in polymers, the experimental complex dielectric permittivity $\varepsilon^{*}(\omega)$ data can be fitted to the HavriliakNagami (HN) model, which can be expressed as a combination of the conductivity term and several HN functions forms as follows [18,19,31,32]:

$$
\varepsilon^{*}(\omega)=-i\left(\frac{\sigma_{d c}}{\varepsilon_{0} \omega}\right)^{N}+\varepsilon_{\infty}+\sum_{k=1,2, \ldots} \frac{\Delta \varepsilon_{k}}{\left[1+\left(i \omega \tau_{H N k}\right)^{1-a}\right]^{b}}
$$

where the first term $\left(\frac{\sigma_{d c}}{\varepsilon_{0} \omega}\right)^{N}$ accounts for the conductivity, and $N$ is an exponent that characterizes the conduction process. The conductivity contribution has the strongest influence at the highest temperature and lowest frequency. The last term is the HN function. The summation symbol indicates the occurrence of more than one relaxation process. $\tau_{H N} k$ is the average characteristic relaxation time of the corresponding process $k . \Delta \varepsilon_{k}$ is the dielectric relaxation strength or intensity. For the fractional shape parameters, $a$ and $b$ describe the linewidth and asymmetry of the relaxation loss peak, respectively, where $a \geq 0$ and $b \leq 1$ hold. When $a=1$ and $b=1$, the linewidth of the relaxation process becomes broad, and its shape is symmetrical.

\section{Results and Discussion}

\subsection{TEM}

To visibly exhibit the filler particles on the rubber matrix, Figure 1 presents transmission electron microscopy (TEM) images of neat NBR, NBR-H20, NBR-H60, NBR-S20, and NBR-S60 samples. Comparing the TEM images of neat NBR and NBRs with fillers, we see that the shape and distributions of the filler were identified. NBR-H20 and NBR-H60 had spherical island shapes with particle sizes of $37 \pm 6 \mathrm{~nm}$. In NBR-S20 and S60, the size of the silica particles was $27 \pm 8 \mathrm{~nm}$. Such particles were distributed as partially condensed aggregates. Specifically, a prominent feature in NBR-H60 is the formation of a percolation channel or network. The shape of the particles is important for electrical conductivity to reach percolation, which requires a channel or network to be formed, such as for NBR-H60. The aspect ratio is defined by the ratio between the horizontal and vertical lengths of the particles. For instance, the larger the aspect ratio, the thinner and longer the particle shape of the filler, and the more advantageous it is to build the percolation path, even if a small amount of loading is added. In the case of NBR-H20 and NBR-H60 with spherical shapes, the aspect ratio was determined to be 1 ; this type of filler particle has the disadvantage of building a percolation path compared to particles that have a large aspect ratio. However, a channel can be formed by increasing the filler concentration, such as NBR-H60, for reaching percolation [33]. 


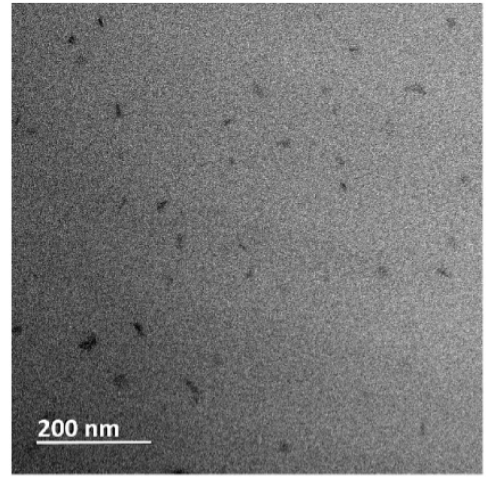

$<$ Neat NBR $>$

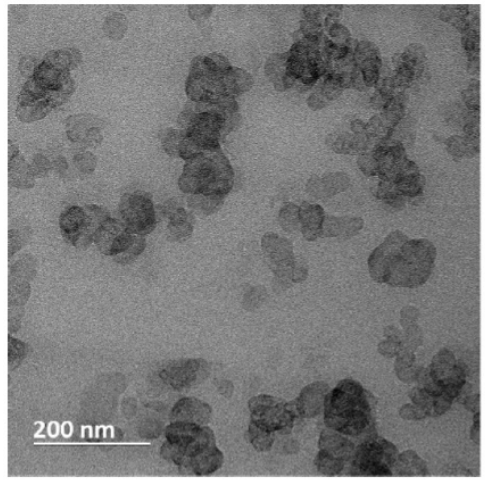

$<$ NBR-H20 $>$

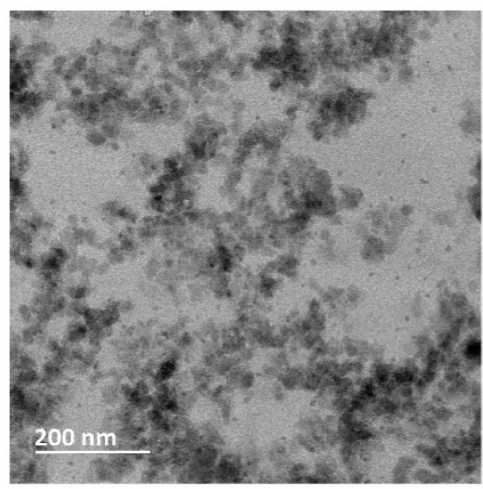

$<$ NBR-S20>

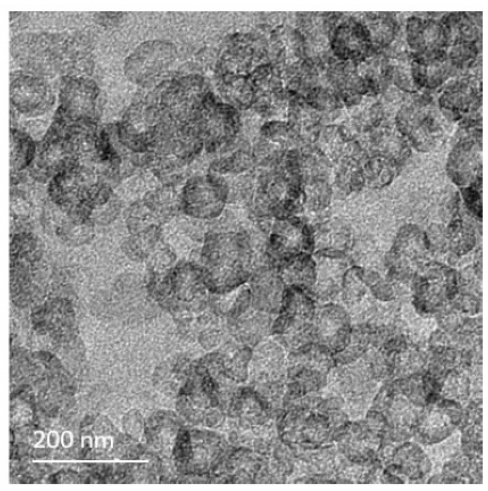

$<$ NBR-H60 $>$

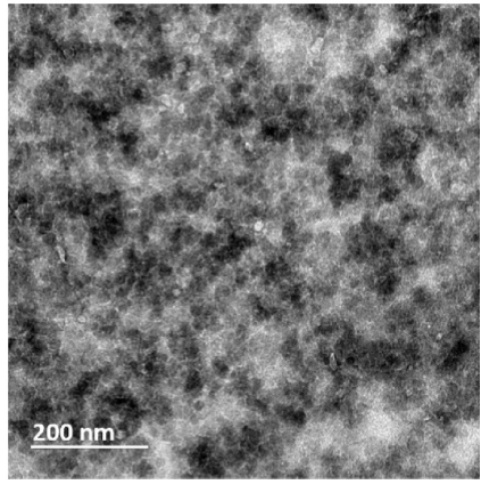

$<$ NBR-S60>

Figure 1. TEM image of neat NBR, NBR-H20, NBR-H60, NBR-S20, and NBR-S60.

\subsection{Impedance Spectroscopy at Room Temperature}

The deconvolution results using self-developed analysis program (Figure S1) obtained for the measured dielectric loss spectra for one neat NBR and nine NBR-H, M, and S series at $298 \mathrm{~K}$ are summarized in Figure 2. From the deconvolution results, we recognize that all specimens had three main relaxation processes, assigned as $\alpha$ and $\alpha^{\prime}$ processes and DC conductivity. Figure $2 \mathrm{a}-\mathrm{c}$ shows the evaluation results for the NBR-H, M, and $S$ series, respectively. The open squares in Figure 2 represent the measured data for the dielectric loss. The simulated sum is represented by a black solid line, which consists of the contributions of the $\alpha$ and $\alpha^{\prime}$ processes (red and black dashed line HN function, respectively) and DC conductivity (purple dashed line). The distinctive feature for the spectrum of the $\alpha$ process is a broad frequency bandwidth (approximately six frequency decades on a logarithmic scale) and an asymmetric shape for a vertical line passing through the central frequency. However, the $\alpha^{\prime}$ process has a comparatively narrow frequency bandwidth (approximately four frequency decades) and symmetric shape for a vertical line passing through the central frequency. The central frequencies of the $\alpha$ and $\alpha^{\prime}$ processes normally appeared near $10^{6} \mathrm{~Hz}$ and $1 \mathrm{~Hz}$, respectively. As mentioned in Section 3, the $\alpha$ process mainly originates from the rotational motion of the segmental chain under the external electric field. The $\alpha^{\prime}$ process originates from the flipping motion of the end-to-end vector of polymer segments in polymer type A. Meanwhile, DC conductivity exhibited a dominant contribution in the low-frequency band, which had a dominant contribution up to $10^{4} \mathrm{~Hz}$ for the neat NBR samples investigated in this study. The distribution of the DC conductivity originates from the migration effect of charge carriers. 


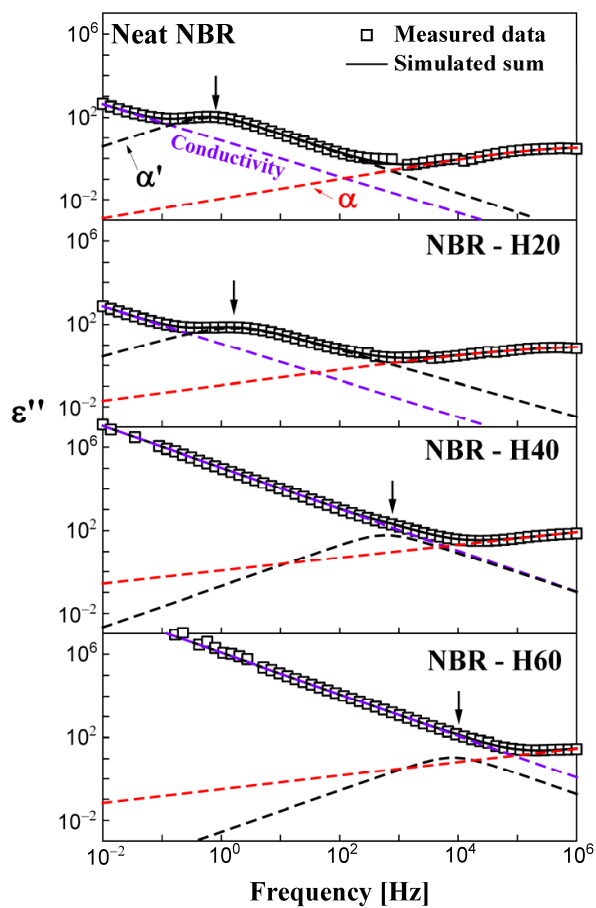

(a)

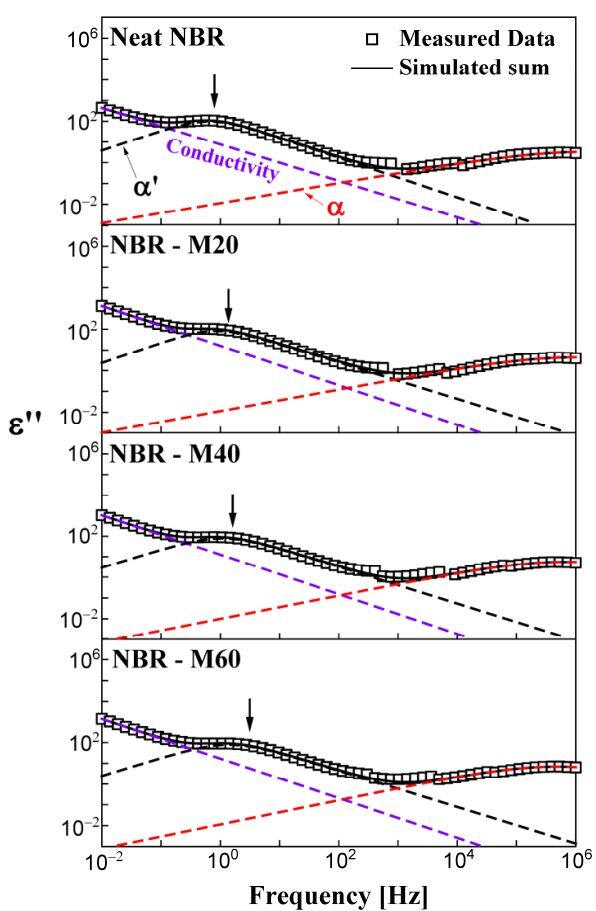

(b)

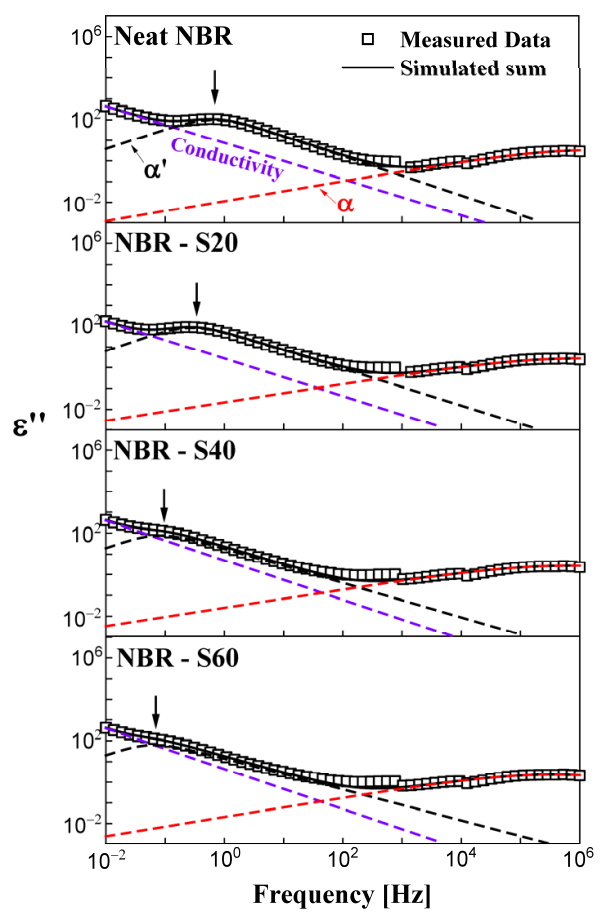

(c)

Figure 2. Influence of filler loading on the dielectric loss spectra in the frequency range from $0.01 \mathrm{~Hz}$ to $1 \mathrm{MHz}$ for neat NBR and (a) NBR-H series, (b) M series, and (c) S series at $298 \mathrm{~K}$. To compare neat NBR and NBRs with filler, we show here three identical neat NBR loss spectra on the top side of each figure $(\mathbf{a}-\mathbf{c})$. The arrows indicate the central frequency for the $\alpha^{\prime}$ process.

From Figure $2 \mathrm{a}-\mathrm{c}$, we see that the central frequency of each relaxation process varied with filler loading at room temperature. In the NBR-H and M series, the central frequency of the $\alpha^{\prime}$ process indicated by arrows was shifted toward the high-frequency side with increasing CB filler concentration, together with increasing conductivity contributions, as indicated by an increase in the area. However, the NBR-S series shifted the central position of the $\alpha^{\prime}$ process to the low-frequency region with increasing silica filler concentration. The shape parameters of the $\alpha^{\prime}$ process for neat NBR were approximately $a=0.05$ and $b=1$. In the $\alpha$ process for neat NBR, the shape parameters were $a=0.48$ and $b=1$. In NBRs with fillers, the shape parameters were similar. Furthermore, the contribution of the conductivity and the position of the central frequency to the $\alpha^{\prime}$ process was influenced by the filler.

The influence of the central frequency for the $\alpha$ process in the NBRs with different filler types and contents on the filler is illustrated in Figure 3. In Figure 3, the central frequency is displayed as a function of filler concentration with uncertainty. In all cases, the central frequency of the $\alpha$ process in the NBR-H, M, and S series scarcely varied with filler type and loading. Likewise, Vieweg et al. [34] reported a similar observation to our study: negligible modification of the central frequency for the $\alpha$ process in styrene-butadiene rubber (SBR) with $\mathrm{CB}$ and silica filler. However, they did not mention the main reason for the negligible influence of the addition of filler on the $\alpha$ process. Similar observations were found in other studies in that the $\alpha$ process did not depend on filler particles, such as carbon nanotubes, zirconium dioxide, carbon black and silica, and polymer composites [35-37]. 


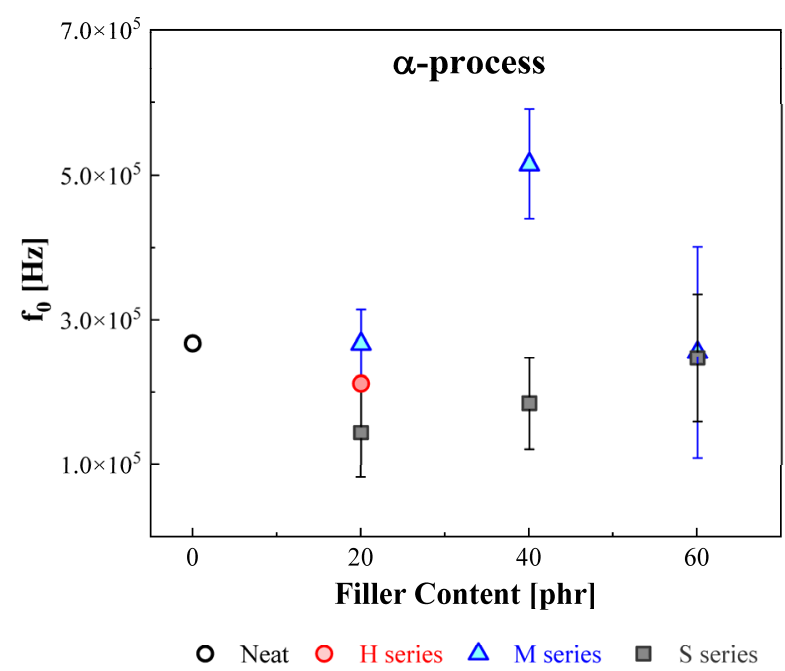

Figure 3. Variation of the central frequency for the $\alpha$ process in NBRs with different filler types and contents. The red circle indicates the $\mathrm{H}$ series, and the blue triangle and gray square symbols indicate the $\mathrm{M}$ and $\mathrm{S}$ series, respectively.

The variations in relaxation frequency for the $\alpha^{\prime}$ process in NBRs with different filler types and contents are displayed in Figure 4, together with the slope of the linear fit between $\mathrm{f}_{0}$ and filler content. The central frequency of the $\alpha^{\prime}$ process in the NBR-H and M series shifted toward the higher frequency side with increasing filler loading. Moreover, the shift rate for the relaxation frequency for the NBR-H series was $10^{4}$ times more significantly influenced by filler content than that for the NBR-M series. It can be explained from the percolation caused by HAF fillers, which is discussed later. Since the particle sizes of the HAF fillers were smaller than those of the MT fillers, the physical crosslink structures of the HAF composites were densely developed. As a result, the molecular mobility of the NBR-H series was significantly decreased compared with that of the MT composites. Therefore, we observed that the central frequency of the $\alpha^{\prime}$ process was highly influenced by the size of the fillers. However, the central frequency for the NBR-S series shifted toward the lower frequency region with increasing filler loading.

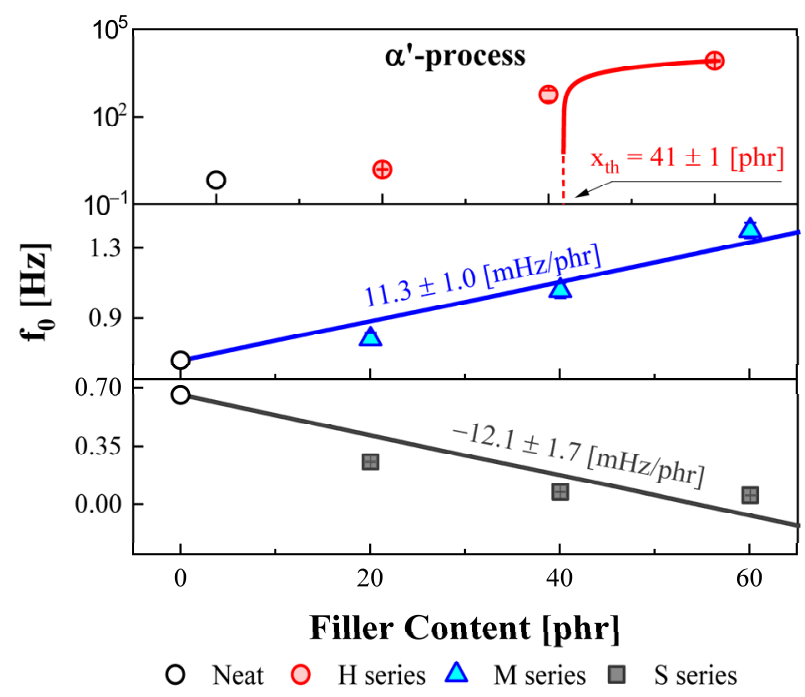

Figure 4. Variation of the central relaxation frequency for the $\alpha^{\prime}$ process with different filler types and contents. The red circle indicates the $\mathrm{H}$ series, and the blue triangle and gray square symbols indicate the $\mathrm{M}$ and $\mathrm{S}$ series, respectively. The red solid line indicates that fitting result of Equation (8) and blue and gray solid lines represent the linear fitting results of $\mathrm{f} 0$ versus the filler concentration. 
This behavior in the NBR-S series can be understood by zero shear viscosity as follows. One of the characteristic features of the dielectric relaxation process of the type-A polymer is the linear dependence of the relaxation time on the zero-shear viscosity $(\eta)$. The general relation between relaxation time and zero-shear viscosity in a non-entangled bulk polymeric system can be written as follows [18]:

$$
\tau_{p}=\frac{12 M \eta}{\pi^{2} \rho R T p^{2}}
$$

where $\eta$ is the zero-shear viscosity, $M$ is the molecular weight, $\rho$ is the density, and $p$ is the $n$-th order of the normal mode relaxation. According to Equation (7), the relaxation time was directly proportional to the zero-shear viscosity of a specimen. In prior research [38], the zero-shear viscosity of a rubber matrix was found to increase with increasing silica concentration. Thus, there was obvious evidence for a decrease in the central frequency for the NBR-S series. In addition, since silica filler also has an electric nonpolar property, the transport phenomenon for charge carriers in polymeric systems will be restricted under an external field. This can be another reason why the relaxation frequency shifts toward the low-frequency side with increasing nonpolar filler content.

The DC conductivity was obtained from the fitting results using Equation (6). The variation in DC conductivity as a function of the HAF, MT, and silica filler loading is shown in Figure 5. The magnitude of the DC conductivity for the NBR-H and M series increased with increasing filler content. However, the DC conductivity for the NBR-S series decreased with increasing filler content. The behavior was similar to the variation in the central frequency for the $\alpha^{\prime}$ process, as shown in Figure 4. In the NBR-H series of Figure 5, the red solid line indicates the fitting result by the described model as follows [39]:

$$
\sigma_{d c}=\sigma_{f}\left(v-v_{c}\right)^{q},\left(v>v_{c}\right)
$$

where $\sigma_{d c}$ is dc conductivity of the composite, $\sigma_{f}$ is the value of filler conductivity. $v, v_{\mathcal{C}}$, and $q$ indicate the filler concentration (loading), percolation threshold, and scaling exponent, respectively. Calculated percolation threshold $v_{\mathcal{c}}$ was found to be $37 \pm 1 \mathrm{phr}$ for the NBR-H series, whose value was obtained by the fitting result. Likewise, in the NBR-H series of Figure 5, the red solid line shows a fitting result $\left(v_{\mathcal{c}}=41 \pm 1 \mathrm{phr}\right)$ using Equation (8). The obtained percolation thresholds for two fitting results showed similar values. In the case of the NBR-H and $\mathrm{M}$ series, since the CB filler has a positive polarity, the transport mechanism for the charge carrier was activated. Consequently, the average DC conductivity of the polymeric system increased with increasing CB loading. However, as mentioned before, since silica filler has a nonpolar property, an external electric field will be shielded. Therefore, the transport phenomenon for the charge carriers will be restricted, and the total DC conductivity in the polymeric system decreased with increasing silica filler content.

Furthermore, the magnitude of the DC conductivity for the NBR-H series was approximately $10^{5}$ times more rapidly varied than that for the NBR-M series. This can be understood by the close correlation between percolation and filler particle size. Since HAF has a smaller particle size $(28 \sim 36 \mathrm{~nm})$ than MT $(250 \sim 350 \mathrm{~nm})$, the percolation path for the NBR-H series was densely developed compared to the M-series. This observation was consistent with the TEM result. As a result, the densely developed percolation path can support the transport mechanism for the charge carrier, which acts as a conductive metal wire. In other words, a small HAF filler is crucial to percolation formation, leading to a drastic increase in conductivity. 


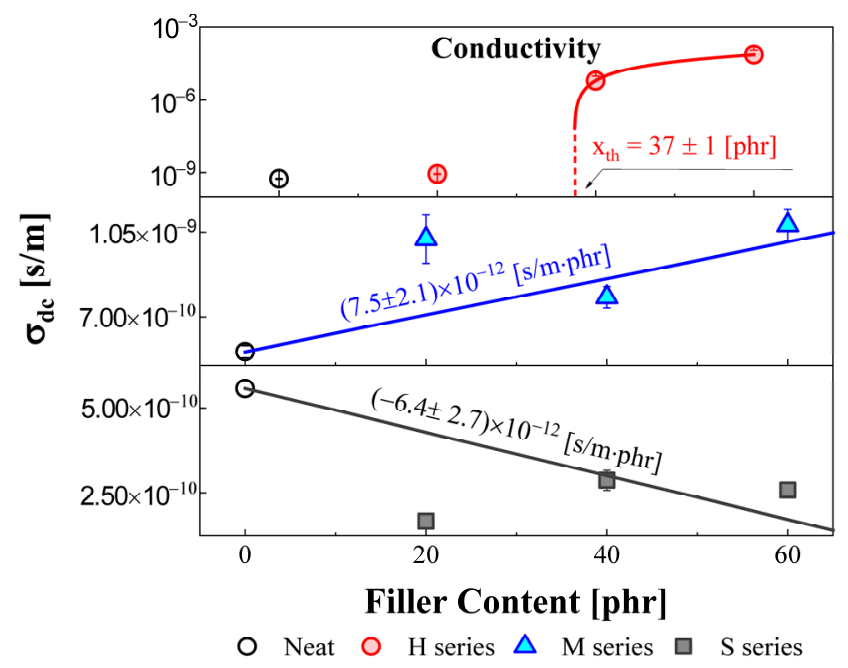

Figure 5. Conductivity for NBRs with different filler types and contents at $298 \mathrm{~K}$. The red circle indicates the $\mathrm{H}$ series, and the blue triangle and gray square symbols indicate the $\mathrm{M}$ and $\mathrm{S}$ series, respectively. The red solid line indicates the fitting result of Equation (8).

\subsection{Temperature Dependence of the Dielectric Relaxation}

The dielectric properties of the NBRs with CB and silica fillers were investigated in the temperature range from $233 \mathrm{~K}$ to $403 \mathrm{~K}$. The measured complex permittivity spectra were analyzed by a modified dispersion analysis program. From this deconvolution process, the central frequency determined for the $\alpha^{\prime}$ and $\alpha$ processes and DC conductivity for neat NBR versus reciprocal temperature is depicted in Figure 6. The DC conductivity and $\alpha^{\prime}$ process were mainly observed in the temperature range from 265 to $403 \mathrm{~K}$, and the $\alpha$ process appeared in the temperature range from 248 to $303 \mathrm{~K}$. The central frequencies for the $\alpha^{\prime}$ and $\alpha$ processes showed a nonlinear dependence for the logarithmic $f_{o}$ and the reciprocal temperature, while the DC conductivity below $370 \mathrm{~K}$ showed a linear variation.

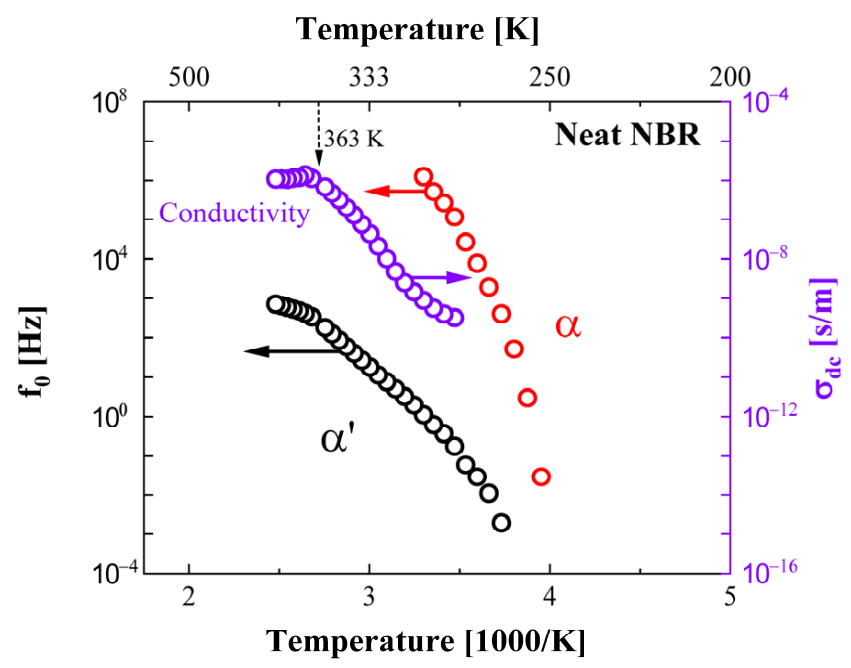

Figure 6. The variation of the central frequency for the $\alpha^{\prime}$ and $\alpha$ relaxation processes and DC conductivity versus reciprocal temperature for neat NBR. The black circles indicate the $\alpha^{\prime}$ process, and the violet and red circles indicate the DC conductivity and $\alpha$ process, respectively.

As the related dynamics of the polymer chain resulted in a sudden change near $\mathrm{T}_{\mathrm{g}}$, the central frequency of the $\alpha$ process had a stronger temperature dependence than the $\alpha^{\prime}$ process and DC conductivity. From this observation, we can qualitatively infer that the $\alpha$ process had higher activation energy than the other two relaxation processes. Meanwhile, the value for the DC conductivity obtained for neat NBR lay in the range of 
$10^{-6}$ to $10^{-10} \mathrm{~S} / \mathrm{m}$, and these values were reasonably comparable to those found for other insulating rubber polymers in the literature [40-43].

Likewise, the central frequency of the $\alpha^{\prime}$ and $\alpha$ processes and DC conductivity versus reciprocal temperature in NBR-H20, M20, and S20 are representatively shown in Figure 7. The overall temperature dependence of all relaxation processes for NBRs on filler content shows behavior similar to that observed for neat NBR. The central frequencies of the $\alpha$ process were mainly distributed in the frequency range between $10^{-3}$ and $10^{6} \mathrm{~Hz}$, and the $\alpha^{\prime}$ relaxation process occurred at approximately $10^{-3}-10^{3} \mathrm{~Hz}$. The DC conductivity was distributed at approximately $10^{-10}-10^{-6} \mathrm{~S} / \mathrm{m}$.

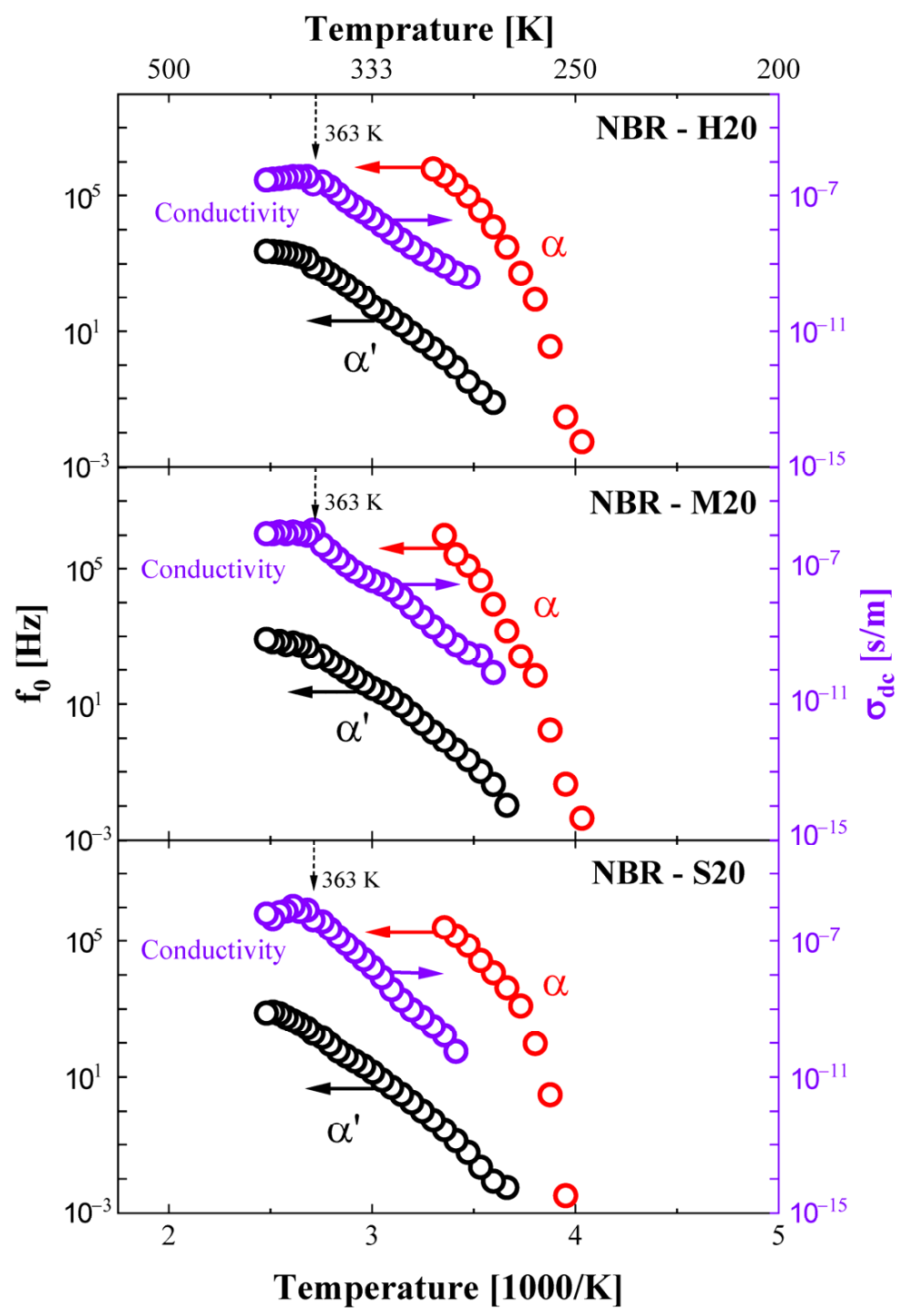

Figure 7. The variation of the central frequency for each relaxation process and DC conductivity as a function of reciprocal temperature for NBR-H20, NBR-M20, and NBR-S20. The black circles indicate the $\alpha^{\prime}$ process, and the violet and red circles indicate the DC conductivity and $\alpha$ process, respectively.

Figure 8 represents the temperature dependence of the central frequency for the $\alpha$ process, as determined from the results of the deconvolution procedure for the dielectric loss spectra. The $\alpha$ process commonly appeared in the temperature range of $248-303 \mathrm{~K}$, except for NBR-H40 and H60. In the case of the highest filler loading, the relaxation rate for segmental dipoles increased with decreasing segmental mobility because of the increased physical crosslink density according to the increased filler loading. Thus, the $\alpha$ relaxation process for NBR-H40 and 60 could not be observed in monitored frequency 
ranges $\left(10^{-2}-10^{6} \mathrm{~Hz}\right)$ [5]. Moreover, in the low-frequency region, since the contribution of DC conductivity rapidly increased with increasing HAF content, the spectra of the $\alpha$ process were hidden in the loss spectra of DC conductivity. Therefore, the deconvolution processes of $\alpha$ process for NBR-H40 and H60 could not be conducted.

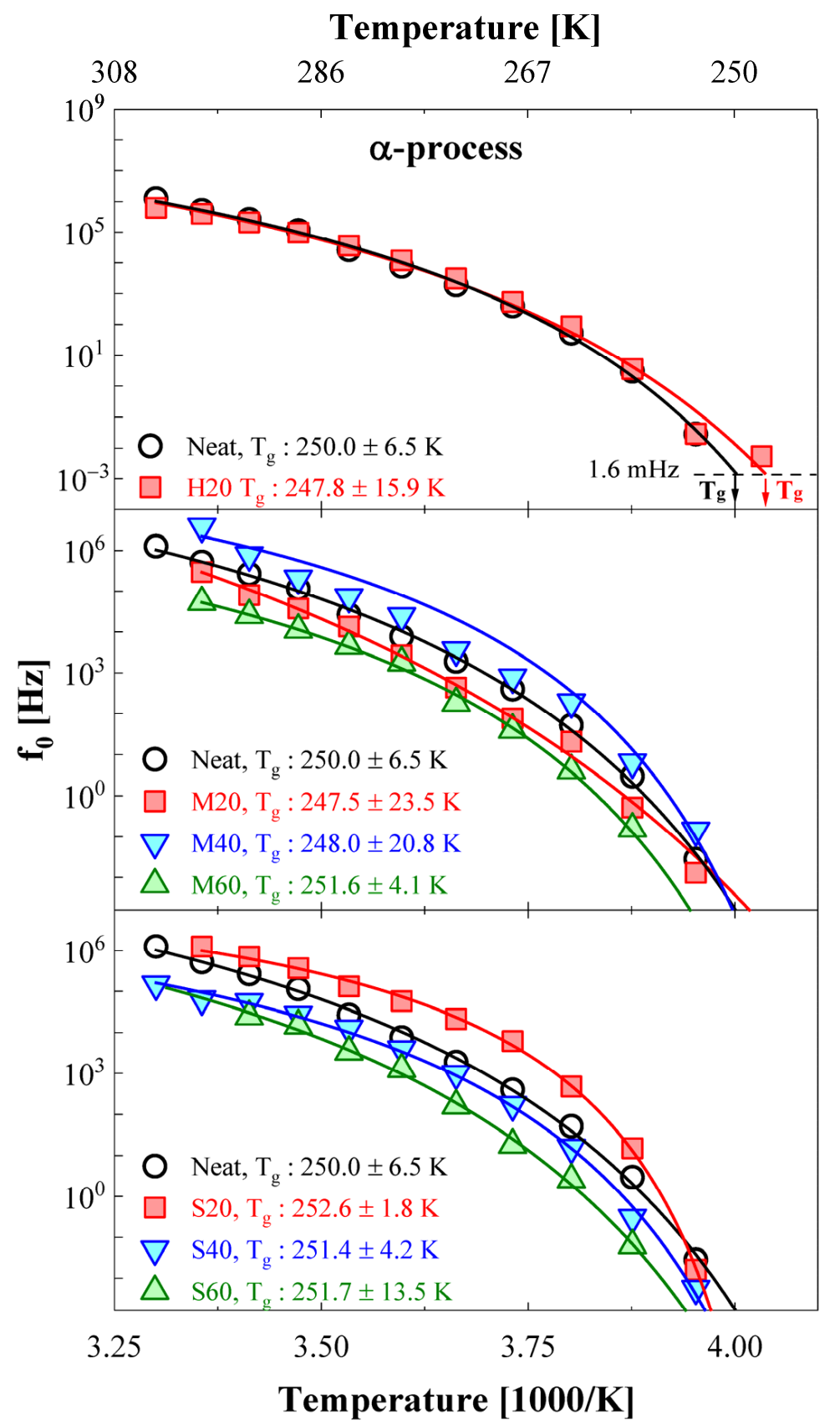

(a)

(b)

(c)

Figure 8. Temperature dependence of the central frequency for the $\alpha$ process on different fillers and contents. (a-c) Each H, M, S series. In (b,c), f0 is multiplied by arbitrary values so that it can be better distinguished by upshifting or downshifting on the frequency axis. For comparison, three identical neat NBR results are shown on the top, middle, and bottom sides of each figure.

In principle, $T_{g}$ is empirically defined as the temperature at which the central frequency described by the VFTH function of Equation (2) reached $1.6 \mathrm{mHz}$, as shown in solid lines of Figure $8 \mathrm{a}$. The $\mathrm{T}_{\mathrm{g}}$ in the $\alpha$ process can be obtained by fitting the relaxation rate for the $\alpha$ process using the VFTH temperature dependence model. In this measurement, due to the lack of sampling points for the $\alpha$ process near $\mathrm{T}_{\mathrm{g}}(250 \mathrm{~K})$, we conducted the calculation on 
the basis of an extrapolation of the fitting results for the VFTH model. The results obtained from a fit of the VFTH model to the relaxation rate of the $\alpha$ process are depicted as a solid line in Figure 8a.

Meanwhile, the $T_{g}$ by DSC measurement in rubber polymer was difficult to define as a single temperature, because of the wide distribution of $\mathrm{T}_{\mathrm{g}}$ in the transition region. However, for comparison with dielectric relaxation spectroscopy (DRS), we tried to define $\mathrm{T}_{\mathrm{g}}$ as a single temperature at which the slope of the tangent line in the heat flow curve had the maximum value between the glass transition regions scanned by DSC analyzer programs. According to the definition, the $\mathrm{T}_{\mathrm{g}}$ was obtained through the DSC measurement.

The $T_{g}$ values obtained using a fitting simulation based on the VFTH model by DRS and DSC were compared in Table 3. The $T_{g}$ obtained for the NBRs with different filler types and contents using the two methods was found to be approximately $250 \mathrm{~K}$. The obtained $\mathrm{T}_{\mathrm{g}}$ value obtained for neat NBR by the DRS method was $250.0 \pm 6.5 \mathrm{~K}$. The $\mathrm{T}_{\mathrm{g}}$ values obtained for neat NBR from DSC measurements were $250.1 \pm 0.2 \mathrm{~K}$. Likewise, the $T_{g}$ for the NBRs with different filler types and contents was measured using DRS and DSC to be in the range of $250.1 \pm 2.5 \mathrm{~K}$ and $248.4 \pm 1.0 \mathrm{~K}$, respectively. The $\mathrm{T}_{\mathrm{g}}$ values obtained by the two different methods had a discrepancy of less than $4 \mathrm{~K}$. Consequently, we found that the DRS and DSC results showed good agreement with each other. However, significant variations in the $\mathrm{T}_{\mathrm{g}}$ values for different filler conditions were not found. Vieweg et al. [34] conducted an investigation into the influence of filler composites on $\mathrm{T}_{\mathrm{g}}$ for reinforced SBR rubber using various $C B$ and silica fillers. They also reported negligible variation in the $T_{g}$ of reinforced SBR.

Table 3. Summary of the $T_{g}$ values obtained with DRS and DSC.

\begin{tabular}{ccccccccc}
\hline & \multicolumn{2}{c}{ Neat NBR } & \multicolumn{2}{c}{ NBR H Series } & \multicolumn{2}{c}{ NBR M Series } & \multicolumn{2}{c}{ NBR S Series } \\
\hline $\begin{array}{c}\text { Contents } \\
(\mathbf{p h r})\end{array}$ & DRS (K) & DSC (K) & DRS (K) & DSC (K) & DRS (K) & DSC (K) & DRS (K) & DSC (K) \\
\hline 0 & $250.0 \pm 6.5$ & $250.1 \pm 0.2$ & - & - & - & - & - & - \\
20 & - & - & $247.8 \pm 15.9$ & $248.6 \pm 0.2$ & $247.5 \pm 23.5$ & $247.8 \pm 0.2$ & $252.6 \pm 1.8$ & $248.0 \pm 0.1$ \\
40 & - & - & - & $249.2 \pm 0.1$ & $248.0 \pm 20.8$ & $248.8 \pm 0.1$ & $251.4 \pm 4.2$ & $249.6 \pm 0.1$ \\
60 & - & - & - & $247.9 \pm 0.1$ & $251.6 \pm 4.1$ & $247.6 \pm 0.1$ & $251.7 \pm 13.5$ & $247.9 \pm 0.1$ \\
\hline
\end{tabular}

Because the glass transition of polymer generally occurred in the broad temperature range, it is difficult to evaluate the influence of $\mathrm{CB}$ and silica fillers on glass transition. Thus, the heat capacity change $\left(\Delta C_{p}\right)$ at the glass transition region was obtained from the DSC heat flow curves divided by heating rate $(\mathrm{K} / \mathrm{min})$ in the region of glass transition (Figure S2). The $\Delta \mathrm{C}_{\mathrm{p}}$ values of NBRs were found to be decreased with increasing the content of $C B$ and silica fillers (Figure 9). The $\Delta C_{p}$ value was strongly related to the volume of the immobilized rubber chains [44]. The decrease in the mobility of the polymer chain is mainly caused by the interaction between rubber chains and surface of the filling agents $[45,46]$. As a consequence, the $\Delta C_{p}$ values of NBRs decrease with increase in the volume fraction of the filling agents. In addition, Mostafa et al. [47] showed the similar result that represented the ability of $\mathrm{CB}$ in NBR to impart greater stiffness to the filled vulcanizates, which reduces the mobility of the rubber chains.

The central frequency of the $\alpha^{\prime}$ process versus reciprocal temperature is shown in Figure 10. The $\alpha^{\prime}$ process generally appears in the temperature range of $268-403 \mathrm{~K}$, except for NBR-H40 and 60. Similar to Figure 8, since the contribution of DC conductivity to the permittivity spectra rapidly increased with increasing HAF filler content, the morphologies of the $\alpha^{\prime}$ process were buried due to the contribution of DC conductivity. Therefore, the fitting procedures in this process could not be conducted. 


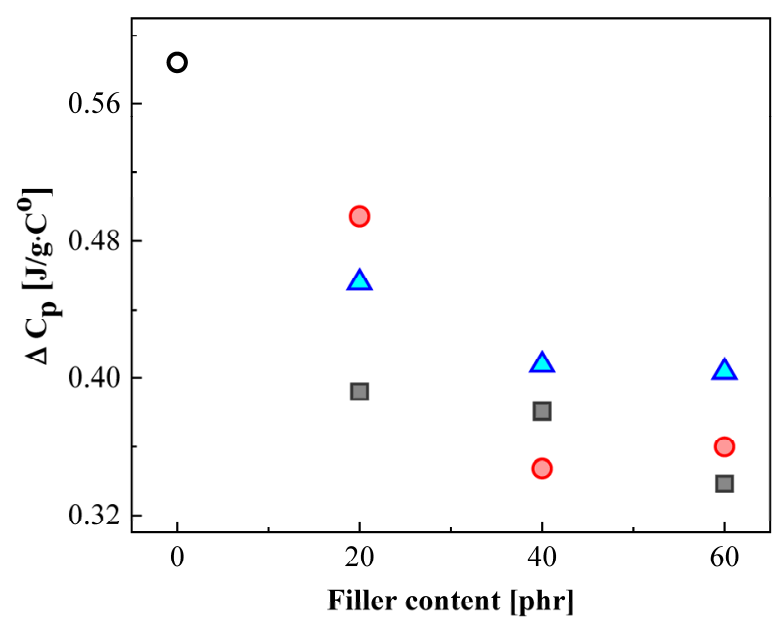

Figure 9. The summarization of obtained Delta $C_{p}$ values as a function of filler content. The empty black circle indicates the result of neat NBR, and the black square, red circle, and blue triangle symbols represent the results of NBR with HAF, MT, and silica fillers, respectively.

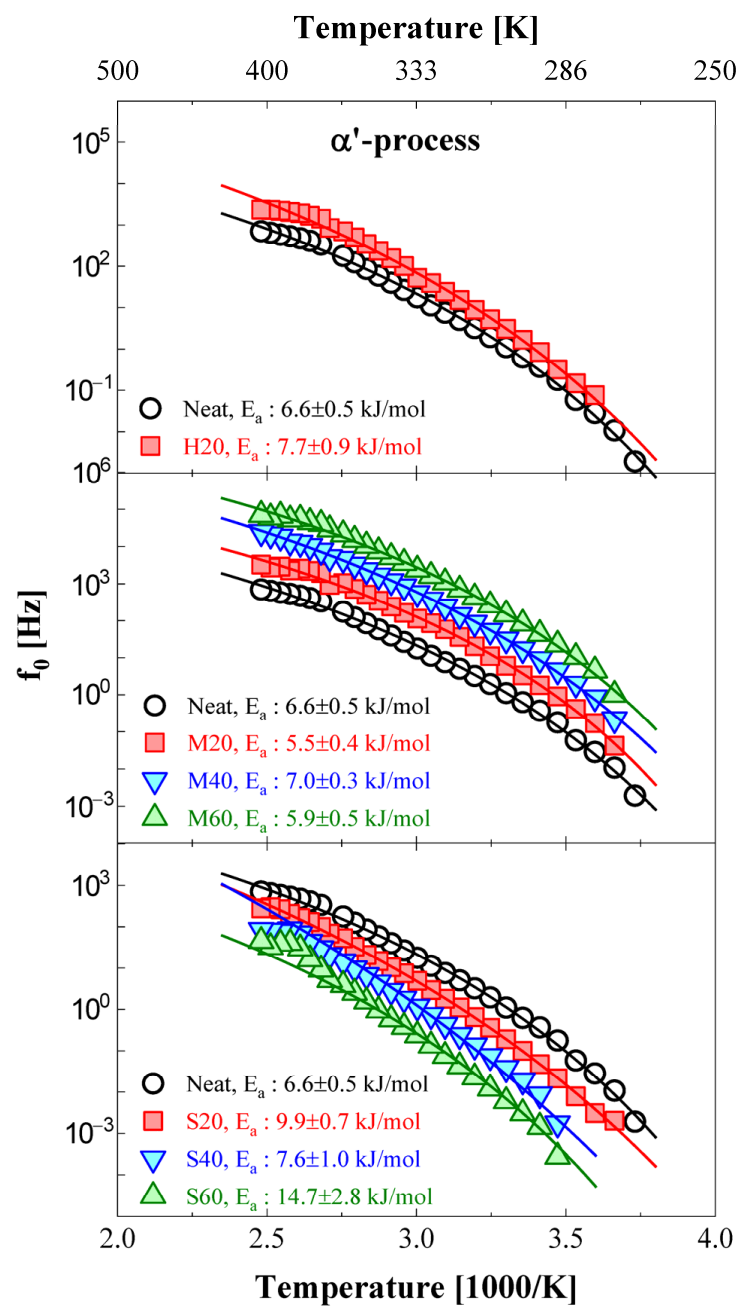

Figure 10. Temperature dependence of the relaxation rate for the $\alpha^{\prime}$ process on different filler loading contents and types. The $\mathrm{f}_{0}$ multiplied by arbitrary values can be better distinguished by downshifting on the frequency axis. For comparison, three identical neat NBR results are shown on the top, middle, and bottom sides of each figure. 
The activation energy for the $\alpha^{\prime}$ process was obtained by the VFTH model Equation (2). The obtained activation energies versus filler content for the $\alpha^{\prime}$ process are displayed in Figure 11. The blue solid lines show the results obtained from a linear fit for the activation energy versus filler concentration for the $\mathrm{M}$ series. From the slope of the linear fitting result for the $M$ series, we see that the activation energies slightly decreased with increasing filler content, while the activation energies of the NBR-S series significantly increased with increasing filler content. This result shows the opposite tendency in the shift behavior for the central frequencies, as shown in Figure 4. In the case of the NBR-S series, the central frequency shifted toward the low-frequency side with increasing filler content, as shown in Figure 4, which is by the variation in activation energy. This means that the motion of the end-to-end vector became interrupted by filler loading, resulting in an increase in the activation energy. The NBRs with CB had a smaller effect on the activation energy than NBR with silica.

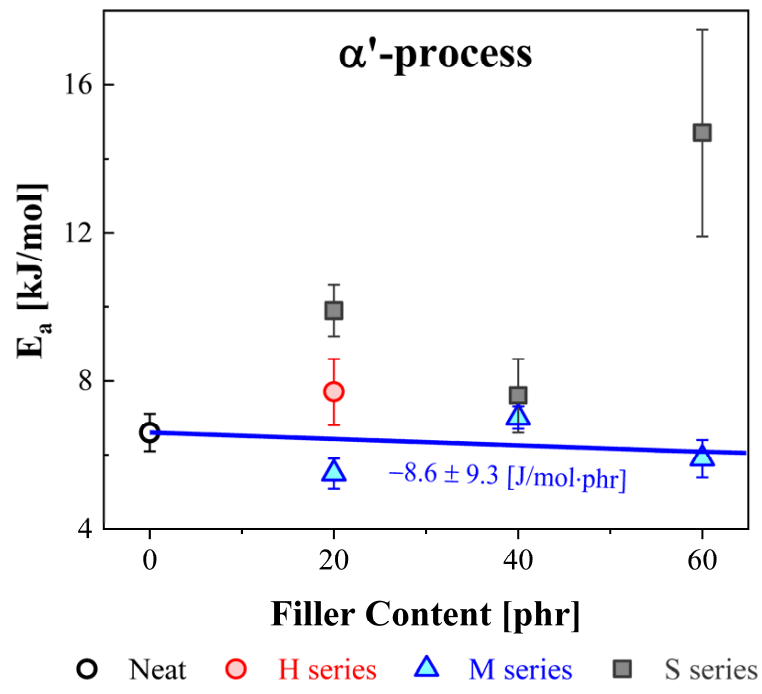

Figure 11. Comparison of activation energy with the different filler loading contents and types. The blue solid lines represent the linear fitting results for the $\mathrm{M}$ series.

Figure 12 shows the temperature dependence of the DC conductivity for neat NBR and NBR-H and the M and S series samples. The activation energy for the DC conductivity can be obtained by fitting the Arrhenius temperature dependence in Equation (5). The solid lines indicate the results of the Arrhenius fitting, and the obtained activation energies are illustrated in Figure 12. The fitting procedure was only performed for the experimental results obtained from 363 to $293 \mathrm{~K}$ because the fitting results above $363 \mathrm{~K}$ deviate from an Arrhenius temperature dependence. The DC conductivity in this temperature region abnormally decreased with increasing temperature. Similar behavior has already been observed in analogous polymeric systems [48-52]. Aziz et al. [51] reported that the main reason for these abnormal behaviors is a phase transition from the crystallized amorphous phase to only the amorphous phase of the polymer host. In addition, Roggero et al. [52] proposed that the decrease in conductivity with increasing temperature is governed by the outgassing process of humid air from polymeric systems. The abnormal behavior observed in this work was strongly influenced by the filler type and content. In the case of CB filler composites (Figure 12), the transition temperature for the abnormal behavior increased with increasing filler content. In contrast, for the case of silica filler composites, the transition temperature inversely decreased with increasing filler content. 
Temperature [K]

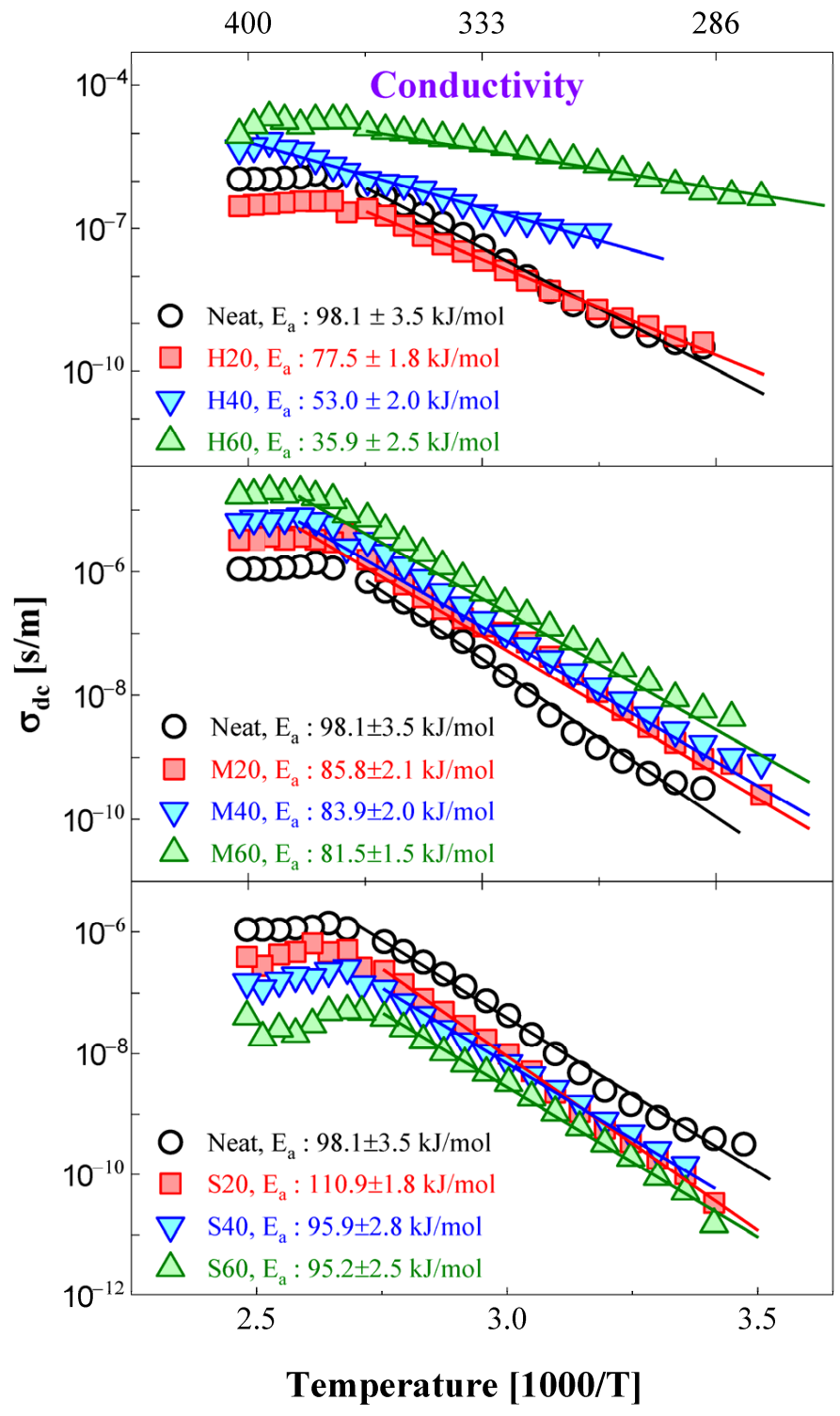

Figure 12. Temperature dependence of DC conductivity for NBR blends with different filler types and contents. The activation energies for each conduction process were determined to show an Arrhenius temperature dependence, as represented by the solid line. The conductivity data multiplied by arbitrary values can be better distinguished by downshifting on the conductivity axis. For comparison, three identical neat NBR results are shown on the top, middle, and bottom sides of each figure.

The obtained activation energies for DC conductivity versus filler content for the $H$, $\mathrm{M}$, and $\mathrm{S}$ series are plotted in Figure 13. For comparison with our result, the activation energies determined for NBRs with HAF by the Yehia Group [53] were indicated as the black-filled circles. The slopes for the four solid lines indicate the results obtained from a linear fit for $E_{a}$ versus filler content. The activation energies for the NBR-S series showed little change with increasing filler content. However, the activation energies for the NBR-H and $\mathrm{M}$ series decreased with increasing filler content. Furthermore, the activation energies for the NBR-H series rapidly decreased with increasing filler content compared with the M series. The rates of decrease in the activation energies are the same within the uncertainty as those reported in [53]. This tendency is also similar to the variation in DC conductivity shown in Figure 5. This phenomenon may arise from the fact that the charge carriers were decoupled from the segmental motion of the polymer chains and the fact that transport occurred via an activated hopping mechanism [54]. 


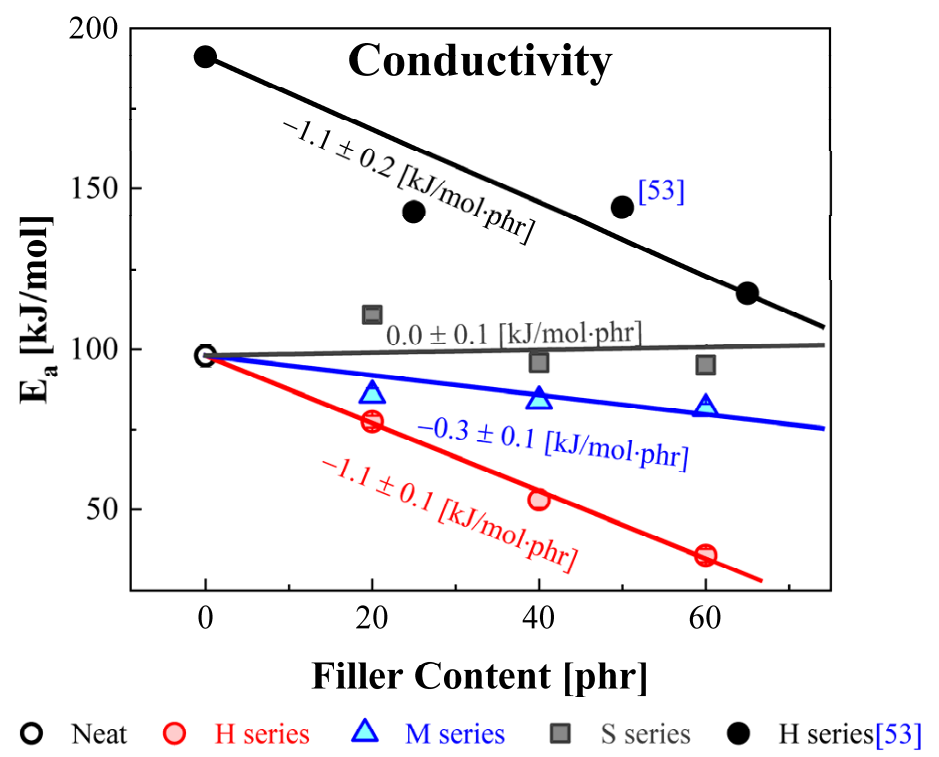

Figure 13. The activation energy for DC conductivity for NBR composites under varying filler loading content. The solid lines and their slopes represent the linear fitting results obtained for the $\mathrm{H}, \mathrm{M}$, and S series.

\section{Conclusions}

The influences of carbon black and silica fillers with different concentrations on the dielectric properties of NBR co-polymer were investigated by using dielectric relaxation spectroscopy (DRS) with a self-developed analysis program. Mainly, the $\alpha$ and $\alpha^{\prime}$ relaxation process and contribution of the DC conductivity were observed in all NBR specimens. The observed complex dielectric spectra were fitted by using the Havriliak-Nagami model and conductivity contribution. The temperature dependencies of the $\alpha$ and $\alpha^{\prime}$ relaxation and DC conductivity followed VFTH and Arrhenius behavior, respectively.

The central frequencies of $\alpha^{\prime}$ relaxation were shifted toward the higher and lower frequency regions with increasing the carbon black and silica fillers, respectively. Moreover, the DC conductivities of NBR were markedly affected by the addition of fillers. Conspicuously, the DC conductivity of the NBR-H series (HAF, N330) was rapidly varied with the addition of HAF fillers. It has been pointed out that the HAF fillers have a great influence on increasing the DC ionic conduction in NBR co-polymer because of the percolation effect. Therefore, the calculation of the percolation threshold using the Equation (8) has been conducted on both $\alpha^{\prime}$ relaxation and DC conductivity of NBR-H series, and the threshold points were obtained to be 37 and $41 \mathrm{phr}$, respectively.

Using the DRS and DSC methods, we measured the glass transition temperature $\left(\mathrm{T}_{\mathrm{g}}\right)$ of all NBR specimens to be in the range of $250.1 \pm 2.5 \mathrm{~K}$ and $248.4 \pm 1.0$. The obtained $\mathrm{T}_{\mathrm{g}}$ using two different methods had good agreement with each other. Furthermore, the heat capacity change $\left(\Delta C_{p}\right)$ values were obtained to evaluate the influence of filling agents on the glass transition. Although the noticeable influences of $C B$ and silica fillers on $T_{g}$ were not found, the results of $\Delta C_{p}$ values were clearly revealed in that the $\Delta C_{p}$ in NBRs decreased with increasing the $C B$ and silica filler. From these results, we identified that the addition of filling agents leads to a decrease in the mobile rubber chains of NBR.

Supplementary Materials: The following supporting information can be downloaded at: https:// www.mdpi.com/article/10.3390/polym14010155/s1, Figure S1: The modified dispersion analysis program; Figure S2: The measured heat flow curves of our NBR specimens by using DSC instrument; Table S1: ASTM classification for type of carbon black. 


\begin{abstract}
Author Contributions: Conceptualization, methodology, writing-review, supervision and project administration, J.-K.J.; visualization, investigation, data analysis, writing—original draft preparation and editing, G.-H.K.; investigation, data analysis, writing-original draft preparation and editing, Y.-I.M.; resources, M.-C.C. and J.-W.B.; All authors have read and agreed to the published version of the manuscript.
\end{abstract}

Funding: This research was supported by the Development of Reliable Measurement Technology for Hydrogen Refueling Stations funded by the Korea Research Institute of Standards and Science (KRISS-2021-GP2021-0007).

Institutional Review Board Statement: Not applicable.

Informed Consent Statement: Not applicable.

Data Availability Statement: The data used to support the findings of this study are available from the corresponding author upon request.

Conflicts of Interest: The authors declare that they have no known competing financial interest or personal relationships that could have appeared to influence the work reported in this paper.

\title{
References
}

1. Khawaja, M.; Sutton, A.P.; Mostofi, A.A. Molecular Simulation of Gas Solubility in Nitrile Butadiene Rubber. J. Phys. Chem. B 2017, 121, 287-297. [CrossRef]

2. Fujiwara, H. Analysis of acrylonitrile butadiene rubber (NBR) expanded with penetrated hydrogen due to high pressure hydrogen exposure. Int. Polym. Sci. Technol. 2017, 44, 41-48. [CrossRef]

3. Barth, R.R.; Simmons, K.L.; Marchi, C.S. Polymers for Hydrogen Infrastructure and Vehicle Fuel Systems: Applications, Properties, and Gap Analysis; Office of Scientific and Technical Information: Oak Ridge, TN, USA, 2013.

4. Polymer Properties Database, O-Ring Seals. 2015. Available online: https://polymerdatabase.com/Elastomers/O-Ring_ Elastomers.html (accessed on 20 November 2020).

5. Nanda, M.; Chaudhary, R.; Tripathy, D. Dielectric relaxation of conductive carbon black reinforced chlorosulfonated polyethylene vulcanizates. Polym. Compos. 2020, 31, 152-162. [CrossRef]

6. Das, N.; Chaki, T.; Khastgir, D.; Chakraborty, A. Electrical and mechanical properties of conductive carbon black filled EVA, EPDM and their blends. Kautsch. Gummi Kunstst. 2002, 55, 300-306.

7. Karasek, L.; Sumita, M. Characterization of dispersion state of filler and polymer-filler interactions in rubber-carbon black composites. J. Mater. Sci. 1996, 31, 281-289. [CrossRef]

8. Liu, J.S.; Wu, S.P.; Chen, M.Z.; Mi, Y.X. The Effect of Filler on the Properties of Silicone Rubber. Mater. Sci. Forum 2009, 620-622, 311-314. [CrossRef]

9. Ulfah, I.M.; Fidyaningsih, R.; Rahayu, S.; Fitriani, D.A.; Saputra, D.A.; Winarto, D.A.; Wisojodharmo, L.A. Influence of Carbon Black and Silica Filler on the Rheological and Mechanical Properties of Natural Rubber Compound. Procedia Chem. 2015, 16, 258-264. [CrossRef]

10. Stöckelhuber, K.W.; Svistkov, A.S.; Pelevin, A.G.; Heinrich, G. Impact of filler surface modiefication on large scale mechanism of Styelne Butadiene/Silica rubber composites. Macromolecules 2011, 44, 4366-4381. [CrossRef]

11. Meier, J.G.; Mani, J.W.; Klüppel, M. Analysis of carbon black networking in elastomers by dielectric spectroscopy. Phys. Rev. B 2007, 75, 054202. [CrossRef]

12. Rattanasom, N.; Saowapark, T.; Deeprasertkul, C. Reinforcement of natural rubber with silica/carbon black hybrid filler. Polym. Test. 2007, 26, 369-377. [CrossRef]

13. Hashim, A.S.; Azahari, B.; Ikeda, Y.; Kohjiya, S. The Effect of Bis(3-Triethoxysilylpropyl) Tetrasulfide on Silica Reinforcement of Styrene-Butadiene Rubber. Rubber Chem. Technol. 1998, 71, 289-299. [CrossRef]

14. Brinke, J.; Debnath, S.; Reuvekamp, L.; Noordermeer, J. Mechanistic aspects of the role of coupling agents in silica-rubber composites. Compos. Sci. Technol. 2003, 63, 1165-1174. [CrossRef]

15. Suzuki, N.; Ito, M.; Ono, S. Effects of rubber/filler interactions on the structural development and mechanical properties of NBR/silica composites. J. Appl. Polym. Sci. 2005, 95, 74-81. [CrossRef]

16. Lopez, J.F.; Perez, L.D.; Lopez, B.L. Effect of silica modification on the chemical interactions in NBR-based composites. J. Appl. Polym. Sci. 2011, 122, 2130-2138. [CrossRef]

17. Wang, W.G.; Li, X.Y. Impedance and dielectric relaxation spectroscopy studies on the calcium modified Na0.5Bi0.44Ca0.06TiO2.97 ceramics. AIP Adv. 2017, 7, 125318. [CrossRef]

18. Runt, J.P.; Fitzgerald, J.J. Dielectric Spectroscopy of Polymeric Materials Fundamentals and Applications, American Chemical Society: Washington, DC. J. Am. Chem. Soc. 1997, 119, 1202.

19. Kremer, F.; Schonhalds, A. Broadband Dielectric Spectroscopy; Springer: Berlin, Germany, 2003.

20. Dastan, D.; Banpurkar, A. Solution processable sol-gel derived titania gate dielectric for organic field effect transistors. J. Mater. Sci. Mater. Electron. 2017, 28, 3851-3859. [CrossRef] 
21. Dastan, D.; Gosavi, S.W.; Chaure, N.B. Studies on electrical properties of hybrid polymeric gate dielectrics for field effect transistors. Macromol. Symp. 2015, 347, 81-86. [CrossRef]

22. Sun, C.; Zhang, P.; Wrana, C.; Schuster, R.; Zhao, S. Combined dielectric and mechanical investigation of filler network percolation behavior, filler-filler contact, and filler-polymer interaction on carbon black-filled hydrogenated acrylonitrile-butadiene rubber. Rubber Chem. Technol. 2014, 87, 647-663. [CrossRef]

23. Xu, H.; Song, Y.; Jia, E.; Zheng, Q. Dynamics heterogeneity in silica-filled nitrile butadiene rubber. J. Appl. Polym. Sci. 2018, 135, 63-67. [CrossRef]

24. Jung, J.K.; Moon, Y.I.; Kim, G.H.; Tak, N.H. Characterization of dielectric relaxation process by impedance spectroscopy for polymers: Nitrile butadiene rubber and ethylene propylene diene monomer. J. Spectrosc. 2020, 2020, 8815492. [CrossRef]

25. Moon, Y.I.; Jung, J.K.; Kim, G.H.; Chung, K.S. Observation of the relaxation process in fluoroelastomers by dielectric relaxation spectroscopy. Phys. B Condens. Matter 2021, 608, 412870. [CrossRef]

26. Stockmayer, W.H. Dielectric dispersion in solution of flexible polymers. Pure Appl. Chem. 1967, 15, 539. [CrossRef]

27. Block, H. The nature and pllication of electrical phenomena in polymers. Adv. Polym. Sci. 1979, 33, 94.

28. Van Krevelen, D.W. Properties of Polymers, 4th ed.; Elsevier: Amsterdam, The Netherlands, 2009.

29. Kakani, S.L. Electronics Theory and Applications; New Age International Publisher: Delhi, India, 2011; p. 7.

30. Dhahri, A.; Dhahri, E.; Hlil, E.K. Electrical conductivity and dielectric behaviour of nanocrystalline La0.6Gd0.1Sr0.3Mn0.75Si0.25O3. RSC Adv. 2018, 8, 9103-9111. [CrossRef]

31. Vassilikou-Dove, A.; Kalogeras, M. Dielectric analysis (DEA). In Thermal Analysis of Polymers, Fundamentals and Applications; Menczel, J.D., Prime, R.B., Eds.; Wiley: New Jersey, NJ, USA, 2009; pp. 497-614.

32. Raju, G.G. Dielectric in Electric Fields; Marcel Dekker Inc.: New York, NY, USA, 2003.

33. Fu, S.Y.; Lauke, B.; Mai, Y.W. Science and Engineering of Short Fiber Reinforced Polymer Composites; Woodhead Publishing: Cambridge, MA, USA, 2009.

34. Vieweg, S.; Unger, R.; Heinrich, G.; Donth, E. Comparison of dynamic shear properties of styrene-butadiene vulcanizates filled with carbon black or polymeric fillers. J. Appl. Polym. Sci. 1999, 73, 495-503. [CrossRef]

35. Zhang, Y.; Wang, W.; Zhang, J.; Ni, Y. Dielectric relaxation processes in PVDF composite. Polym. Test. 2020, 91, 10680. [CrossRef]

36. Robertson, C.G.; Lin, C.J.; Rackaitis, M.; Roland, C.M. Influence of Particle Size and Polymer-Filler Coupling on Viscoelastic Glass Transition of Particle-Reinforced Polymers. Macromolecules 2008, 41, 2727-2731. [CrossRef]

37. Robertson, C.; Roland, C.M. Glass Transition and Interfacial Segmental Dynamics in Polymer-Particle Composites. Rubber Chem. Technol. 2008, 81, 506-522. [CrossRef]

38. Gurovich, D.; Macosko, C.W.; Tirrell, M. The Influence of Filler-Filler and Filler-Polymer Interactions on the Physical Properties of Silica-Filled Liquid Polyisoprene. Rubber Chem. Technol. 2004, 77, 1-12. [CrossRef]

39. Vikulova, M.; Tsyganov, A.; Bainyashev, A.; Artyukhov, D.; Gorokhovsky, A.; Muratov, D.; Gorshkov, N. Dielectric properties of PMMA/KCTO (H) composites for electronics components. J. Appl. Polym. Sci. 2021, 138, 51168. [CrossRef]

40. Moon, Y.I.; Jung, J.K.; Chung, K.S. Dielectric Relaxation Spectroscopy in Synthetic Rubber Polymers: Nitrile Butadiene Rubber and Ethylene Propylene Diene Monomer. Adv. Mater. Sci. Eng. 2020, 2020, 8406059. [CrossRef]

41. Pissis, P.; Fragiadakis, D.; Kanapitsas, A. Broadband Dielectric Spectroscopy for Studying Morphology and Interfacial Effects in Polymer Nanocomposites (n.d.). In Proceedings of the 11th European Conference on Conposite materials-ECCM11, Rhodes, Greece, 31 May-3 June 2004.

42. AlZamil, M.A.; Alfaramawi, K.; Abboudy, S.; Abulnasr, L. Temperature Coefficients of Electrical Conductivity and Conduction Mechanisms in Butyl Rubber-Carbon Black Composites. J. Electron. Mater. 2017, 47, 1665-1672. [CrossRef]

43. Nguyen, D.H.; Sylvestre, A.; Gonon, P.; Rowe, S. Dielectric properties analysis of silicone rubber. In Proceedings of the 2004 IEEE International Conference on Solid Dielectrics, Toulouse, France, 5-9 July 2004; pp. 103-106.

44. Dong, H.; Jia, Z.; Chen, Y.; Luo, Y.; Zhong, B.; Jia, D. One-pot method to reduce and functionalize graphene oxide via vulcanization accelerator for robust elastomer composites with high thermal conductivity. Compos. Sci. Technol. 2018, 164, 267-273. [CrossRef]

45. Fröhlich, J.; Niedermeier, W.; Luginsland, H.D. The effect of filler-filler and filler-elastomer interaction on rubber reinforcement. Compos. Part A Appl. Sci. Manuf. 2005, 36, 449-460. [CrossRef]

46. Litvinov, V.M.; Orza, R.A.; Klüppel, M.; van Duin, M.; Magusin, P.C.M.M. Rubber-Filler Interactions and Network Structure in Relation to Stress-Strain Behavior of Vulcanized, Carbon Black Filled EPDM. Macromolecules 2011, 44, 4887-4900. [CrossRef]

47. Mostafa, A.; Abouel-Kasem, A.; Bayoumi, M.R.; El-Sebaie, M.G. Rubber-filler interactions and its effect in rheological and mechanical properties of filled compounds. J. Test. Eval. 2010, 38, JTE101942.

48. Ammari, F.; Dardouri, M.; Kahlaoui, M.; Meganem, F. Structure and Electrical Study of New Chemically Modified Poly(vinyl chloride). Int. J. Polym. Sci. 2015, 2015, 280325. [CrossRef]

49. Hasan, N.; Pulst, M.; Samiullah, M.H.; Kressler, J. Comparison of Li+ -ion conductivity in linear and crosslinked poly(ethylene oxide). J. Polym. Sci. Part B Polym. Phys. 2019, 57, 21-28. [CrossRef]

50. Kotobuki, M. Polymer electrolytes: State of the art. In Polymer Electrolytes: Characterization Techniques and Energy Applications; Winie, T., Arof, A.K., Thomas, S., Eds.; Wiley-VCH Verlag: Weinheim, Germany, 2020; pp. 1-21.

51. Aziz, S.B.; Woo, T.J.; Kadir, M.; Ahmed, H.M. A conceptual review on polymer electrolytes and ion transport models. J. Sci. Adv. Mater. Devices 2018, 3, 1-17. [CrossRef] 
52. Roggero, A.; Caussé, N.; Dantras, E.; Villareal, L.; Santos, A.; Pébère, N. Thermal activation of impedance measurements on an epoxy coating for the corrosion protection: 1. dielectric spectroscopy response in the dry state. Electrochim. Acta 2019, 303, 239-245. [CrossRef]

53. Morsy, R.; Ismaiel, M.; Yehia, A. Conductivity studies on acrylonitrile butadiene rubber loaded with different types of carbon blacks. Int. J. Mater. Methods Technol. 2013, 1, 22-35. [CrossRef]

54. Cho, M.; Seo, H.; Nam, J.; Choi, H.; Koo, J.; Lee, Y. High ionic conductivity and mechanical strength of solid polymer electrolytes based on NBR/ionic liquid and its application to an electrochemical actuator. Sens. Actuators B Chem. 2007, 128, 70-74. [CrossRef] 